\title{
Fontanières, Sannat, Reterre
}

\section{Michel Blondonnet}

\section{OpenEdition \\ Journals}

Édition électronique

URL : http://journals.openedition.org/adlfi/7997

ISSN : 2114-0502

Éditeur

Ministère de la culture

Référence électronique

Michel Blondonnet, «Fontanières, Sannat, Reterre », ADLFI. Archéologie de la France - Informations [En ligne], Limousin, mis en ligne le 01 mars 2005, consulté le 01 mai 2019. URL : http:// journals.openedition.org/adlfi/7997

Ce document a été généré automatiquement le 1 mai 2019.

(c) Ministère de la Culture et de la Communication, CNRS 


\title{
Fontanières, Sannat, Reterre
}

\author{
Michel Blondonnet
}

Identifiant de l'opération archéologique : 122357

Date de l'opération : 2005 (PR)

1 En 2005 notre travail a principalement porté sur la vérification des fiches des communes de Fontanières, Reterre et Sannat. Nous avons corrigé au passage de nombreuses erreurs de numéros de parcelles et rectifié des coordonnées parfois complètement fantaisistes sur la carte au $1 / 25000^{e}$. Malgré nos recherches, un tiers d'entre elles n'ont pu être situées pour l'instant du fait du manque de précision des mentions apportées initialement par les auteurs de ces fiches.

2 À noter que deux trésors monétaires étaient signalés, l'un à La Louche, l'autre à La Petite Louche (Sannat), alors qu'il s'agissait en fait d'un seul et même dépôt.

3 Nous avons réussi à situer également avec certitude le "retranchement quadrangulaire de $92 \mathrm{~m} \times 84 \mathrm{~m}$ de Fontanières appelé aussi "Camp de César", alors que jusqu'ici on n'avait pu le faire. Dans cette dernière commune nous avons d'ores et déjà trouvé une douzaine d'autres sites que nous n'avons pu signaler cette année faute de temps. Nous ne manquerons pas de le faire l'année prochaine. Il faut dire que seules quatre fiches existent à ce jour pour la commune de Fontanières et qu'il y a donc potentiellement matière à répertorier de nouveaux sites, avec notamment ce microtoponyme prometteur, Les souhaits et les rondelles, qui pourrait être le témoin d'un lieu de culte très certainement lié à une ancienne source.

4 En ce qui concerne la commune de Rougnat, nous avons pu mener à bien un sondage archéologique dans la parcelle cadastrée BD108, appelée St-Hilaire. Enfin, s'agissant de la commune d'Auzances, nous avons signalé que des travaux de déviation d'une portion du lit de la rivière Noisette risquaient de détruire un pont répertorié par nos soins lors d'un précédent rapport. (Fig. $n^{\circ} 1$ : Pont sur la Noisette) 
Ce pont se trouve sur la Noisette, au beau milieu d'un champ, à l'écart de tout cheminement actuel. Après réflexion et étude sur carte, la voie antique déjà signalée par le Dr Janicaud, qui passait notamment à Létrade (Cne de Rougnat), pouvait tout à fait couper la Noisette en cet endroit. Cette voie n'apparait pas en continu sur la carte au $1 / 25000^{\circ}$ mais nous l'avons suivie au sol sur plusieurs kilomètres depuis ce village. Elle passe entre Lépinard et Chabouteix, continue à l'ouest de Chamassergue et rejoint la D4 à hauteur du Puy Rigaud. Elle devait ensuite emprunter la route actuelle qu'elle quittait probablement sur la droite à hauteur du Puy du Mas pour se diriger vers Le Faux, ferme située en bordure ouest de la ville d'Auzances, où l'on perd sa trace. Ce tronçon est d'ailleurs sûrement très ancien puisque qu'il délimite à cet endroit les communes d'Auzances et de Rougnat.

6 À $300 \mathrm{~m}$ du village du Faux, en bordure de cette voie, il convient de rappeler que trois tumuliont été repérés et signalés depuis longtemps. Notre sentiment est que cette voie devait continuer dans la même direction et couper la Noisette vers la laiterie, que l'on projette d'agrandir sur l'actuel lit de la rivière, une fois la déviation réalisée, avant de continuer vers Le Montaud, Marcillat et peut-être un autre village appelé aussi Létrade, commune des Mars. L'amorce de ce tronçon est visible sur la carte et le fait qu'il y ait une croix à cet endroit est significatif d'une voie et d'un carrefour autrefois très fréquentés.

7 Tout ceci expliquerait, c'est du moins l'hypothèse que nous avançons, la présence de ce pont en cet endroit incongru. (À noter qu'il existe à proximité immédiate de ce pont une éminence sur laquelle nous avons recueilli de nombreux tessons de céramiques - difficilement datables -, et un fragment de silex poli qui témoignent d'une occupation probable à une époque indéterminée. Il conviendra donc d'être vigilant si l'on autorise les travaux de dérivation du lit de la Noisette à l'issue de l'enquête publique prévue).

Ce pont a été élargi à une époque indéterminée, ce qui nous renforce dans notre conviction qu'il était bien situé sur un très ancien passage. Il ne doit avoir que trois ou quatre cents ans mais nous pensons qu'il a dû en remplacer un autre, qui a peut-être lui aussi pris le relais d'un de ses ancêtres. Avouons qu'il serait dommage qu'un témoin d'une voie aujourd'hui disparue, antique ou pas, disparaisse à son tour.

Michel Blondonnet

\section{ANNEXES}


Fig. $\mathrm{n}^{\circ} 1$ : Pont sur la Noisette

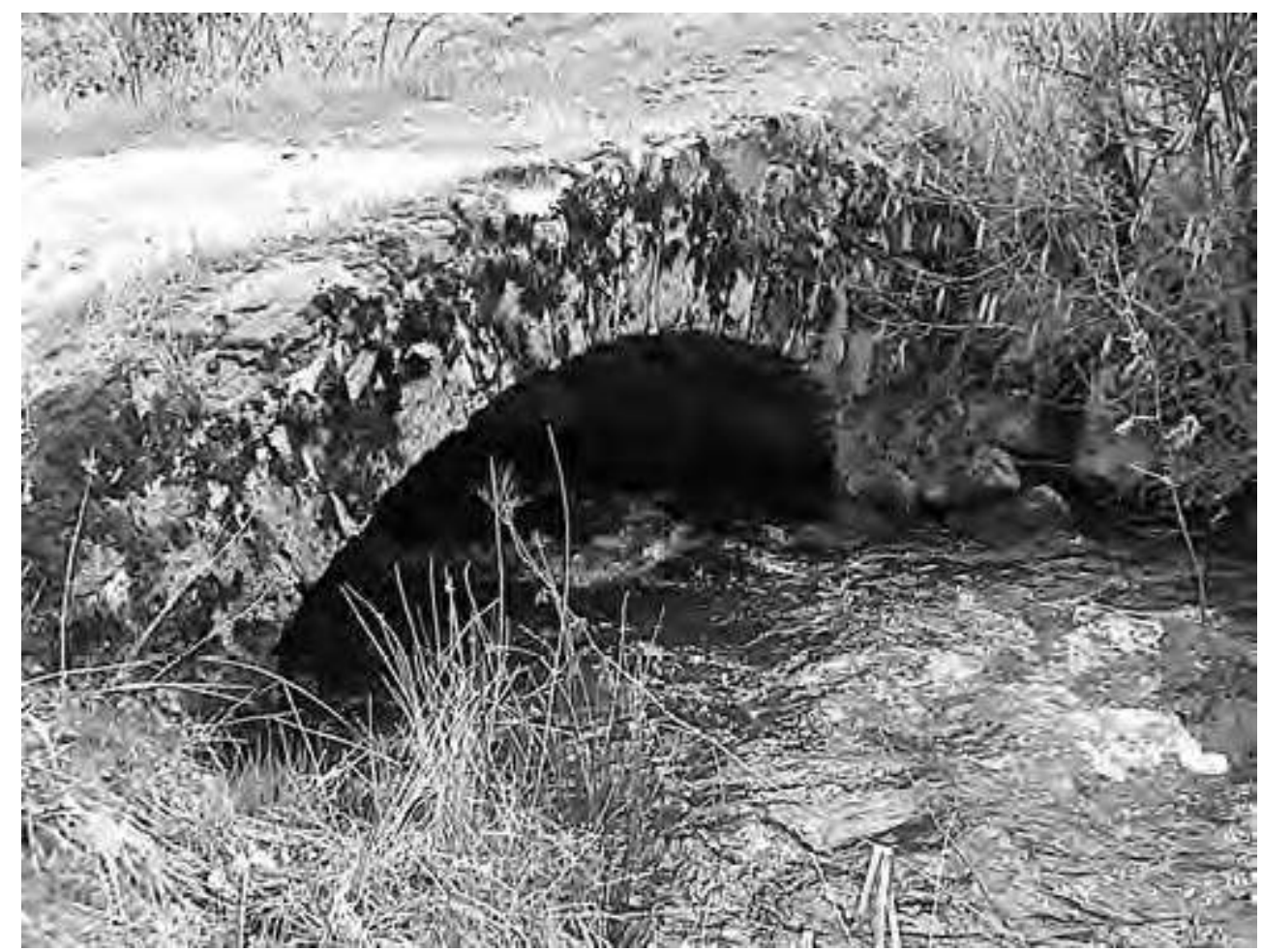

Auteur(s) : Blondonnet, Miche (BEN). Crédits : Blondonnet Michel, BEN (2005)

\section{INDEX}

operation Prospection (PR)

Index chronologique : Empire romain

Thèmes : camp, cartographie, céramique, cours d'eau, lieu de culte, monnaie, pont, trésor monétaire, tumulus, voie romaine

Index géographique : Limousin, Creuse (23), Fontanières

\section{AUTEURS}

\section{MICHEL BLONDONNET}

BEN 